percentage of all respondents $(64 \%)$. Predictably, despite continuing evidence to the contrary, ${ }^{45}$ advances in antemortem diagnostic techniques offsetting the need for necropsy were considered important by $54 \%$ of all respondents. Failure of junior doctors to ask for relatives' consent and an increased reluctance on their part to give consent were considered important by $53 \%$ and $52 \%$, respectively. Failure of pathologists to communicate their findings and increased aesthetic or emotional objections of clinicians to necropsy were considered important by only $18 \%$ and $16 \%$ of respondents, respectively.

We feel that the somewhat negative attitude to the necropsy expressed by junior clinical staff in our survey and the acknowledgement that medical education is lacking in this area are important, as it is frequently the most junior of doctors who are called on to ask a relative's consent for necropsy. We agree with the conclusions of Benbow that more care, effort, and sensitivity must be shown in the training of future doctors with regard to the necropsy.' Only then, perhaps, may the current unacceptable decline in the hospital necropsy rate be halted.

AP GILES
R DOSHI
GG MENON
MK KHAN
Departments of Histopathology and Neuropathology,
Brook General Hospital,
Shooters Hill, London SE18 $4 \mathrm{LW}$

1 Benbow EW. Medical students' views on necropsies. J Clin Pathol 1990;43:969-76.

Cameron HM. Future of the hospital autopsy. Br J Hosp Med 1988;40:335.

3 Frederici HHR. Reflections on the postmortem audit. $J A M A$. 1988;260:3461-5.

4 Goldman L, Sayon R, Robbins S, Conn LH, Bettmann $M$, Weisberg $M$. The value of the autopsy in three medical eras. $N$ Engl $\mathrm{J} \mathrm{Med}$ 1983;308:1000-5.

5 Stevanovic G, Tucakovic G, Dotlic R, Kanjuh $\mathrm{V}$. Correlation of clinical diagnoses with autopsy findings. Hum Pathol 1986;17 $1225-30$.

\section{Eponyms in pathology}

We are impressed by the series on eponyms in pathology. For extra finesse, another detail could be added, namely a note on the pronunciation of names.

An example of why this is necessary is given by the surname of the great Rudolf Ludwig Karl Virchow. Medical students and doctors have a variety of ways of pronouncing his name, often along the lines of verr-chow, to rhyme with per-plough, with the ch pronounced as in chew, or verr-koff, among several others.

Of 14 medical dictionaries and other works of reference in the Barnes Medical Library, University of Birmingham, all of which mention Virchow, only four gave a pronunciation: one said feer-show, one said verr-ko, one said fir-ko, and one, Webster's Medical Dictionary, said fir-cho, with the major stress on the first syllable, the $i$ as in hit, the $c h$ as in German ich or Scottish loch, and the $o$ as in go. According to RH Major, ${ }^{2}$ Virchow himself regarded the appropriate pronunciation as fir-cho.

It can be argued that there is no correct way to pronounce a name, but it is interesting, if nothing else, to find out how a person pronounced their own name. Your series could take the opportunity to educate pathologists with information that cannot always be worked out from first principles.

AJ HOWIE SJ LEE Department of Pathology, iversity of Birmingham Birmingham B15 2TT

1 Virchow-Robin space. Webster's Medical Desk Dictionary. Springfield, Massachusetts: Merriam-Webster, 1986:759.

2 Major RH. Classic descriptions of disease with biographical sketches of the authors. Springfield Illinois: Thomas, 1932:469-71.

Dr Paola Domizio, who contributed the series on eponyms that is currently running in the Journal as space permits, comments:

I sympathise with Drs Howie and Lee that there is no guidance on how to pronounce eponymous terms. I wish it were possible. There are two difficulties. One is that usually when a person's name is given to a condition he or she is dead, and records may not survive of precisely how the name was pronounced. The other is that English freely assimilates foreign words and phrases and gives its own flavour to them. We do not speak of the Vulffian duct or the Artoose reaction, and we would probably not be able to do justice to shigellosis in the way that Shiga would have pronounced it.

To try to answer the specific question, our German senior house officer says Verchoff (the ch as in loch), Springer Verlag in London, who act for Virchow's Archiv in Berlin say Vershow (rhyme with cow), and the managing editor in London, Professor Colin Berry, says Verkow (again, rhyme with cow). I telephoned Berlin on the number given in the current international periodicals directory, and got a night-club.

Contributions to this and related series are welcomed. Please send your contributions to $\mathrm{Dr}$ Domizio at St Bartholomew's Hospital, London EC1A $7 B E$, or to the Editorial Office.

\section{BOOK REVIEWS}

All titles reviewed here are available from the BMJ Bookshop, PO Box 295, London WC1H 9TE. Prices include postage in the United Kingdom and for members of the British Forces Overseas, but overseas customers should add $£ 2$ per item for postage and packing. Payment can be made by cheque in sterling drawn on a United Kingdom bank, or by credit card (Mastercard, Visa or American Express) stating card number, expiratory date, and your full name.

Medicine and Management: Proceedings of the 9th Trent Region Seminar on Pathology. Ed J Pemberton. (Pp 64; soft cover, no price given). Trent RHA. 1990. ISBN 0951-1957-86.

The subjects dealt with at this seminar held by the Trent regional health authority included laboratories and management, molecular pathology, telepathology, the interface between research, teaching and diagnostic pathology, and laboratory accreditation. Pathologists and others with an interest in pathology, its development, management and involvement in patient management are advised to read this valuable seminar report. Pathologists will take heart that Dr Metters, deputy Chief Medical Officer, Department of Health, who discussed the future of pathology in England and Wales, is quoted as saying, "The trend for pathologists to take on a greater clinical workload should be encouraged. The risk, if it is not, will be the tendency to see the laboratory simply as a factory, to produce test results. That would be very retrograde",

In an important final paragraph Dr Metters reasons as follows: "To conclude on a note of optimism: although at present the consequences of the White Paper for pathology may not be clear, speculation about the future is not necessary as pathology has a fundamental part to play in the diagnostic services of the NHS. If the diagnostic service is not right, the therapy won't be either. So whatever happens as a result of the White Paper fundamental importance must be attached to maintaining the quality of the pathology service and its vital contribution to diagnosis and treatment. Whilst pressures on staffing and cost efficiency may be on the increase, it remains essential that pathology services continue to provide an effective, on the spot, 24 hour service for all NHS hospitals, whether they are directly managed by Health Authorities or run by self governing trusts" Pathologists will wholeheartedly agree with Dr Metters' sentiments.

C ROBERTS

Manual of Laboratory Immunology. 2nd ed. LE Miller, HR Ludke, JE Peacock, RH Tomar. (Pp 427; £25.56.) Lea \& Febiger. 1991. ISBN 0-8121-1319-5

This is the second edition of what, the authors claim, is a procedural manual of humoral and cellular immunology intended for a range of laboratory professionals. It starts with a commendably short and concise introduction to immunology with two sound chapters on specimen handling and the principles of serological methods.

The chapter on lymphocyte assessment occurs early, but it is not particularly easy to follow, nor can one easily discern the practical procedures required. It does not start by discussing the sample collection and handling (non-refrigeration, time from venesection to testing, etc.). It gives the uses of the techniques and discusses the principles, and at the end provides the practical instructions.

The section on immunoglobulins is disappointing and does not discuss the relative merits of radial diffusion and other automated fluid phase techniques widely used today. The characterisation of paraproteins is covered by immunoelectrophoresis and immunofixation, but there is no discussion of Bence Jones protein detection or paraprotein quantitation and its problems. Likewise, the section on complement is disappointing. While it goes into some detail of the complement pathways and the various complement deficiencies, it does not indicate the problems of quantitation of individual components, which ones 
should be used, and when, and what the results mean, etc. The only methods described in detail are the classic Kabat and Mayer CH50 technique, and, incredibly, a semiquantitative immunochemical assessment of $\mathrm{Cl}$ esterase inhibitor by Ouchterlony double diffusion.

It has a section on other serum proteins and cytokines, but almost all the methodology is derived from the use of commercial kits. There are no useful practical hints on measuring cytokines. The chapter on phagocytes is mostly theory on the type of abnormalities which occur in clinical practice. The only test procedure described is the screening nitro blue tetrazolium reduction test.

About a third of the book is concerned with infectious disease serology. While these are undoubtedly tests using immunological methodology, they are regarded in this country as being in the intellectual and practical arena of diagnostic microbiology. Laboratory tests in medical immunology are mainly applied to the assessment of abnormalities of the immune system.

The last four chapters are on tests in allergy and autoimmunity and those for tumour markers and HLA antigens. Again, most of the procedures described rely on the use of commercial kits, the Abbot enzyme immunoassay kit being described for the measurement of total IgE. But while a number of pitfalls and problems of the test were described, no mention was made of tests for specific IgE antibodies and their clinical importance.

A major flaw throughout is that little mention is made of the problems of standardsfor the analytes and for the reagents. Nor is enough emphasis given to quality control, both internal and external quality assurance. No mention is made of the techniques of molecular biology, which, in 1991, is surprising.

Overall, this book is disappointing. It has too many omissions and places too much reliance on kits available in the American market to be of much practical value to laboratory immunologists in the United Kingdom.

RA THOMPSON

Papillomaviruses in Human Pathology: Recent Progress in Epidermoid Precancers (Serono Symposia Publications from Raven Press, Vol 78). Ed J Monsonego. (Pp 555; \$109.) Raven Press. 1990. ISBN 0-88167-674-8.

This is volume 78 of the Serono Symposium Publications Series begun in 1982, and contains the contributions to a symposium of the above title held in 1990: the papers have been reproduced with little or no editing, reflecting a variety of both presentation and quality. Sixty contributions to the symposia are included under seven separate headings of fundamental aspects (six papers), gynaecology (16 papers), dermatology (six papers), proctology (eight papers), supra-diaphragmmatic sites (10 papers), the laboratory detection of HPV DNA (11 papers), and basic research (three papers). Each paper is esentially a review of a subject by an author or group of authors, and each paper is referenced to $1988 / 89$. In total, over 150 authors have contributed to the volume of over 550 pages.
Contributions to the proceedings come from numerous laboratories in Europe, the USA, and Canada, but over two thirds are from France; the book suffers a little from this chauvinism because some topics could have been dealt with more authoritatively by research groups who were not represented. The symposium covered a wide field, and each contribution reviews one aspect of the subject matter: this includes contributions from basic scientists and virologists, physicians, surgeons, paediatricians, pathologists and psychologists. For specialists, there is little that has not been published before on his or her specialty, but the contributions on subjects peripheral to specific interests represent a competent review of published findings.

The book will not be essential to individual researchers working specifically in one of the various aspects of the subject, and it is very expensive. The book would be of value in a library of a large department or hospital where access to reviews on subjects related to a specialist interest are required. Finally, the subject of the symposium is moving rapidly: because the book contains little opinion and speculation for the future, it will probably soon become dated.

CW POTTER

Leukaemia Diagnosis. A Guide to the FAB Classification. BJ Bain. (Pp 116; $£ 39.50$.) Gower Medical Publishing. 1990. ISBN 0-397-44608-X.

Titles are more important than many authors realise. One might be forgiven for assuming that this book is simply about the FAB typing of leukaemias, but one would be wrong. It is a comprehensive practical guide to the diagnosis and classification of all types of leukaemia and myelodysplasia, and offers a broad current review of the morphological, cytochemical, immunological and cytogenetic features of malignant blood disorders. The text is complemented by copious high quality colour figures and attractive easy-toread colour-coded tables and diagrams.

Dr Bain is to be congratulated on assembling such a work and presenting it in an admirably succinct and readable way. It neatly fills a gap in the market and will prove invaluable to all haematologists of all levels of experience; the trainee struggling to learn the craft, the generalist confronted with a "difficult" leukaemia, and (perhaps most importantly) the expert who needs a surreptitious source of reference for reassurance.

Because of the pace of developments in molecular and cytogenetics, the half life of at least some sections of the book will be short, so it is to be hoped that the author is already at work on the second edition.

JS LILLEYMAN

Childhood Leukemia: Present Problems and Future Aspects. Proceedings of the Second International Symposium on Children's Cancer. 1989. Tokyo. Eds N Kobayashi, T Akera, S Mizutani. (Pp 265; £40.50.) Kluwer Academic Publishers. 1991. ISBN 0-7923-1138-8.
Eighteen months ago a symposium was held in Tokyo to commemorate the twentieth anniversary of the Children's Cancer Association of Japan at which 13 eminent speakers from Germany, the USA and the UK joined with 20 local speakers to produce what looks like an exciting meeting. I suppose it's incumbent on me as a reviewer to produce the usual tedious list of contents-biology, epidemiology, treatment, and supportive care of childhood leukaemia, to cut a long story short.

I certainly found the book interesting, and it would be of some value to anyone willing to while away a few days trying to bring themselves up to date. Each contribution at least has the considerable merit of brevity. It goes without saying that the quality of contribution varies enormously and it is a good example of how this type of text rarely conveys the vibrancy of the meeting. Examples of the problems of this genre are the anecdotal and skimpy nature of the contribution on infection and the more artistic than scientific nature of the transplant review. I find selective conglomerations of other people's non-randomised bone marrow transplant data, with minimal information to make it meaningful (when was the relapse and where and at what age, etc), of absolutely no value whatsoever in planning treatment. Surely the day of these pedlars of survival curves is over. I also despair when within a few pages one finds results of leukaemia treatment expressed as event free interval, survival, event free rate, event free survival and leukaemia free survival, not to mention the various stratifications for varying risk factors. What am I supposed to make of this? Not a lot, frankly, but an authoritative review of all of these chauvinistic points of view might have educated me rather than making me feel that they are neatly demonstrating various ways of skinning a cat.

Shivers run down my spine when I see a section devoted to psychosocial support. This was better than most, and some of it was even understandable. The United Kingdom contribution, in particular, was written in English and contained thoughtful views. It would be immensely valuable if there was an international convention to ban the use of the following words from such chapters: joinder, experiential, critiquing, caregiver, impacts, renege, outreach, collegial, empowerment, wellness, socialization, kids and networking. This would perhaps help to avoid the usual oleaginous or dolorous approaches.

That having been said, I really did learn a lot from the excellent biology and epidemiology sections, although it is now time to spare us from the multitudinous tedious gels. The information on late effects would have been greatly enhanced by contributions from international experts.

IAN M HANN

Medical Laboratory Haematology. 2nd ed. R Hall, RG Malia. (Pp 736; 660.00 .) Butterworth-Heinemann Ltd. 1991. ISBN 07506-1000-X.

When I reviewed the first edition of this text elsewhere in 1984, I remarked that, in its field, it was a "tour de force". It still is. Not 